\title{
Voicing Strategies Employed in Narrow Listening Among Iranian Female Freshmen
}

\author{
Mohsen Shahrokhi (Corresponding author) \\ Department of English, Shahreza Branch, Islamic Azad University \\ Isfahan, Iran. Tel: 0098-3213292214 \\ E-mail: shahrokhi@iaush.ac.ir \\ Farinaz Shirani Bidabadi \\ Department of English, Shahreza Branch, Islamic Azad University \\ Isfahan, Iran. Tel: 00989133165699; E-mail: f_sh3000@yahoo.com \\ Hamidah Yamat \\ Faculty of Education, University Kebangsaan Malaysia, 43600 UKM Bangi, Malaysia \\ Tel: (+603) 89216338; E-mail: hya@ukm.my
}

Received: 06-02-2013

doi:10.7575/aiac.ijalel.v.2n.3p.138
Accepted: 24-03-2013

Published: 01-05-2013

\begin{abstract}
This study discusses the findings of a qualitative study on the strategies used by Iranian female freshmen in narrow listening. The data collected through semi-structured interview with 12 female freshmen (four learners as advanced, four as intermediate and four as low) chosen purposefully based on their scores in the Oxford Placement Test administered. Six out of 12 freshmen were identified for the think-aloud protocol to draw out the strategies they used. The data collected were analyzed using open, axial, and selective-coding. The analysis of the participants' interview and think-aloud protocol data generated 12 major themes. Five themes (attention, readiness, evaluating, autonomous learning, and change the speech rate) described meta-cognitive; five themes (imitating and repeating, references, visualization, making notes while listening and word-by-word and sentence-by-sentence attention) described cognitive strategies and two themes (asking for help, self-talk) described socio-affective strategies. These strategies need to be taught explicitly to increase learners' understanding of the spoken texts in the second/foreign language. This study recommends that Iranian EFL female freshman university learners' top-down, bottom-up processing and listening strategy awareness should be cultivated and integrated into the teaching of listening to improve the learners' listening ability.
\end{abstract}

Keywords: Narrow listening, listening strategies, listening proficiency, female freshmen, EFL Learners

\section{Background of the Study}

Listening is a complex, active process in which listeners must recognize the distinction and discriminate between speech sounds, understand vocabulary and grammatical structures (syntax), interpret stress and intonation, retain and interpret this within the socio-cultural context of the utterance (Vandergrift, 1992; 1997a; 1999; 2004; 2011; and Yang, 2009, p. 134). Of the four language skills, listening is the most important skill for a second/foreign language (L2/FL) learning as it internalizes the rules of language and facilitates the emergence of other language skills (Dunkel, 1991; Rost, 2002; Vandergrift, 2007; 2011). It is important in everyday life and in education. It is an important skill in language learning and foreign language classrooms (Nunan, 1999). In the context of this study, Iran, listening skill receives very little attention. Many Iranian TEFL (Teaching English as a Foreign Language) learners are not able to use this skill effectively because the learners generally have very restricted oral exposure to English listening materials. The English listening skills are less paid attention and sometimes neglected in many academic classes. This may have serious effect on the learners' English listening proficiency levels. Therefore, in order to improve the learners' listening abilities and skills, many instructors believe that one of the ways of improving English language learners' listening skills is to spend time listening to materials in their target language (Yonezawa and Ware, 2008). It is also essential for EFL learners to listen frequently to spoken texts in English because it is difficult for them to construct a high quality output without appropriate input. Hence, in order to understand the meaning of each word, phrase, and sentence narrow (repeated) listening is required. Narrow listening refers to listening to a piece of genuine listening material about two to three minutes long over and over again until the listener achieves sufficient comprehension and an alternative resource for dealing with uncontrolled speech (Krashen, 1996). It is appropriate to second/foreign language (L2/FL) learners who find uncontrolled casual conversations too difficult to understand particularly with low level of language listening proficiency (Krashen, 1996; Dupuy, 1999). When learners are involved in narrow listening, they need to listen to a text several times, analyze the paragraphs and understand each element of the utterance. Narrow listening also provides a great amount of input that makes the listening texts understandable through repeated listening and familiarity with 
topics (Krashen, 1996; Dupuy, 1999; Caspino, 2005; Macaro, 2003; Liu, 2006). To this end, there should be some strategies used in narrow listening to contribute second/foreign language listeners to comprehend a spoken text. To the knowledge of the researchers, so far, strategies employed in narrow listening has not received any attention. Thus, it is essential to explore how these strategies are employed in narrow listening (listening to a spoken text several times) by Iranian EFL female freshman university learners of three different English listening proficiency levels (advanced, intermediate, and low).

\subsection{Narrow Listening}

With narrow listening learners listen to a piece of English passage or dialogue as many times as they intend and get better understanding (Dupuy, 1999; Krashen, 1996) and after repeated listening, parts of the passage will become automatic (Anderson, 1995). Therefore, the listeners start to think about the listening text and have a personal response to it (affective strategy) (Liu, 2006). According to Anderson $(1983,1995)$, when a learner listens to a passage, she has to engage in perception, parsing, and utilization to understand the continuous audio input. On the other hand, some second/foreign language (L2/FL) low-proficient learners are mostly doing perception and parsing, and rarely reach the stage of utilization when they listen to a listening text (Goh, 2000). Listeners utilize different listening strategies while engaged in perceptual processing, parsing, and utilization (O'Malley, Chamot and Kupper, 1989). If learners are stuck in perception and parsing, they are not able to reach the phase of utilization; thus the use of listening strategies will be restricted. Narrow listening may contribute listeners to reach the phases of perception (encoding the written message) and parsing (identifying parts of the utterance), and involve in more parsing and utilization (making inferences). Narrow listening also helps learners employ specific meta-cognitive, cognitive, and socio-affective listening strategies to understand a spoken text (Liu, 2006). For example, in the first time of listening, listeners listen to a spoken text they recognize which parts they have already understood and which parts they have not understood yet. Then, in the second or third time of listening, they listen to the very text they are likely to plan to listen for the listening parts that they did not understand in the first time of listening (meta-cognitive strategy-planning) (Liu, 2006). Then, in the following times while listening, some parts of the listening text become automatic (Anderson 1983, 1995). After that, the learners may start to guess the meanings of unknown words, phrases and sentences. In this case, they are encouraged to infer (cognitive strategy- inferencing). Finally, the listeners may be encouraged to employ specific socio-affective strategies (Liu, 2006). Therefore, there should be some strategies employed by second/foreign language (L2/FL) learners while engaged in narrow listening.

Meanwhile, some research studies (Krashen, 1996; Dupuy, 1999; Caspino, 2005) investigated the effect of narrow listening on listening comprehension. They reported that listening comprehension enhances due to repetition of the message -a case supported by Krashen's experience in learning Spanish in Mexico. He found that through narrow listening, his Spanish listening ability improved thus he suggested that narrow listening might be useful based on his personal experience. Then, he recommended that narrow listening be utilized in classrooms. Later on Dupuy (1999) investigated the effectiveness of narrow listening on a group of 255 students learning French at a public university in the USA. Dupuy found that the majority of the students, both at the low (first and second semester) and intermediate (third and fourth semester) levels, pointed out that narrow listening was helpful in improving their French. In another study, Caspino (2005) aimed to find the reaction of the students towards narrow listening and the assessment of it as a learner resource. The findings of Caspino's study revealed that all students reported that narrow listening contributed them to improve their English language. They believed that narrow listening was better than listening resources they had already used. Majority of the students found narrow listening was very helpful for improving their listening, pronunciation and all other categories except grammar. In general, Krashen's (1996) personal experience and the findings of Dupuy (1999) and Caspino's (2005) studies showed positive result of narrow (repeated) listening. They all believe that narrow listening can increase second or foreign language learners' listening comprehension. Tokeshi (2006) further reported that repeating key words in spoken text is also effective in increasing the listeners' listening comprehension. It has comprehension benefits whether or not the input rate of subsequent presentations lessened. In some cases repetition alone proved to be more effective in enhancing comprehension than simplification (Jensen \& Vinther, 2003; Brown, 2007) and repeated listening is a comprehension strategy used by all learners, when circumstances permit (Smidt \& Hegelheimer, 2004; Brown, 2007). Re-listening to incompletely understood input would seem to be a common sense tactic, but it is one that many students, despite their declared interest in learning English, do not consistently use (Brown, 2005; Brown, 2007).

\section{The Study}

The aim of the interview and think-aloud methods in this study was to draw out strategies employed by Iranian EFL female freshman university learners in narrow listening. A small number of learners were selected because the aim was to learn and understand the central phenomenon (Creswell, 2002). A group of 12 female freshmen aged 18 were purposefully chosen in order to avoid the possibility of the learners who were more exposed to the language due to their age difference as well as gender to impact on the results of the study. Also, these learners were chosen as participants of this study because they are at the low level of tertiary/higher education in which they need to have a competence in English language particularly in listening skills to ensure their performance in their studies. They were from five classes at a university in Esfahan, Iran. They were majoring in Teaching English as a Foreign Language (TEFL). Based on the results of their English listening proficiency levels (Oxford Placement Test developed by Oxford University Press Allan (1992)) four learners were identified as advanced $(A L 1=96, A L 2=80, A L 3=86, A L 4=89)$ four learners as intermediate (IL1=66, IL2=61, IL3 =65, IL4=63) and four learners as low $(L L 1=28, L L 2=33, L L 3=23, L L 4=30)$. Then, a group of six 
freshmen out of 12 freshmen were purposefully chosen based on the findings of the interviews for conducting the thinkaloud protocol (two from advanced (AL1, AL4), two from intermediate (IL1, IL3) and two from low (LL2, LL4)). These freshmen were those who were more able to express their inner thoughts as they underwent the listening process. Each conversation was played three times. The interviews and think-aloud sessions took about thirty to forty-five minutes on average each. The interviewees were allowed to speak in their mother tongue (Farsi) in order to enable them to express their perceptions towards the use of listening strategies better. The semi-structured interview and think-aloud guide both developed before the study began. All the interviews and think-aloud data were tape-recorded for verbatim transcription and coding.

After gathering the data from the interviews and think-aloud sessions, each interview and think-aloud session was transcribed as verbatim transcription. The transcriptions were then copied and given to the interviewees to be checked to find out if the content and translation reflected what they said during the interview and think-aloud protocol sessions. After that, the interviews and think-aloud protocol transcripts were analyzed by using three types of coding: opencoding, axial-coding, and selective-coding (Strauss and Corbin, 1998; Richards, 2003). More importantly, the data were coded based on O'Malley and Chamot's (1990) taxonomy adapted for listening comprehension by Vandergrift (1996, 1997).

\subsection{Listening Texts}

The audio tapes (three conversations) extracted from a book entitled Interchange Intro. It is in the Third Edition of Richards's (2005). He asserted that Interchange Third Edition is a revision of New Interchange, the world's most successful and popular English course. These Interchange books are practical, reliable, incorporative active learning, and exposing the learners with real life situations by using live conversations. They include a great number of everyday and live conversations.

\section{Findings and Interpretations}

The findings of the interview and think-aloud protocols revealed several similarities and differences that emerged in the ways participants reported what and how they employed strategies. They were also engaged in thinking about the input they presumably understood during the think-aloud session. By using top-down and bottom-up strategies, they elaborated on what they heard. The analysis of the participants' data generated 12 themes. Five themes (attention, readiness, evaluating, autonomous learning, and change the speech rate) described meta-cognitive; five themes (imitating and repeating, references, visualization, making notes while listening and word-by-word and sentence-bysentence attention) described cognitive strategies and two themes (asking for help, self-talk) described socio-affective strategies which are discussed in the following:

\subsection{Attention}

The first theme paying attention to details coded as attention. The findings indicated that all freshmen except IL3 and IL1 reported that when they were involved in narrow listening they tried to pay attention to key words, pronunciation of words, intonation and tone of voice, parts of speech of the words, and accent. In other words, they paid attention to the details and small units of speech. This indicates that these freshmen acknowledged that they attended to linguistic cues in order to recognize grammatical word classes such as nouns, verbs, and adjectives. This was confirmed through the data gathered from think-aloud protocols. The learners tried to pay attention to details in the listening tasks to comprehend the whole meaning of the conversations even though they could not comprehend some unknown words. They kept on listening and tried to do some segmental comprehension. For example, AL1 reported that in the first time of listening to the first conversation she tried to get the general meaning of the conversation and tried to understand the reason why there is a reporter in the street. This indicates that she concentrated on the content of the spoken texts and tried to ignore some irrelevant distracters. However, she could not recognize where exactly this conversation took place as she said that she thought the speakers were somewhere she did not know may be in the street. This shows that she was attending to the main points to get the key words and then realizes the general meaning. In the second and particularly third time of listening, she paid more attention and she could understand some more words as she said that this time she understood the words 'station', and 'street', 'gym' and 'friend'. This indicates that repetition can make listeners to understand more words and comprehend better. All freshmen asserted that they could understand more and more as they repeated listening to the same conversation. LL2 also asserted that for the first time while she was listening to the conversation, it was very difficult, the speakers were speaking very fast she just heard some words such as 'gym, play, friend'. In the second and third time of listening, she stopped tape-recorder and said that this time (second time) she could understand more and the listening seemed easier to her. This indicates that the second and third time of listening to the same listening text make listeners attend to more key words, phrases, and sentences. This implies that repetition contributes learners to understand the listening texts more effectively. In contrast, LL3 stated that she understood better if she paid attention to the situations and places where the conversation took place. IL1 also said that she focused on the situation where the conversation took place. These indicate that paying attention to these clues such as situation and context of the listening may contribute them to understand the listening texts better. This implies that the context often assists learners to understand the particular meaning of the words, phrases and sentences.

\subsection{Readiness}

The second theme emerged from the interviews coded as readiness refers to a process of thinking about the actions required to deal with a listening task. AL1 said that she made herself ready by looking at the upcoming questions usually before the class starts and she practiced with her friends. AL2 expressed herself in another way: If the listening 
text has a listening transcription at the end of the book, she will read it at least once. AL4 said that when she was listening for the second time or more she tried to find answers for WHQs such as who, where, when, and how questions in the listening task. IL3 also said that sometimes she previewed the upcoming questions such as multiple-choice questions or filling-in the gap statements; IL2 also said that she often previewed the questions and listened to the parts related to the upcoming questions of the listening in the second time of listening; and LL4 said that she was reading the transcription of the listening text. These freshmen claimed that in narrow listening they prepared themselves based on some understandable information such as pre-reading the listening texts and browsing the listening gap filling statements, true and false statements and multiple-choice questions before the second time of listening and using the known information to answer the listening questions. This indicates that these freshmen use these strategies to help them perform well in the listening tasks. It also indicates that employing these strategies can help them understand the spoken texts more effectively. This implies that during narrow listening because of preparation they do after any time of listening, they can complete the missing information they have not understood in the first or second time of listening. Meanwhile, readiness in narrow listening classified into the interactive processing because majority of the freshmen preferred to look at the comprehension questions and preview the specific and needed information in the listening text in order to understand it completely.

\subsection{Evaluating}

The third theme coded as evaluating is a kind of top-down process employed by these freshmen to facilitate their understanding in the listening process in narrow listening. AL3 said that she listened to the listening text to check what she has heard earlier matches with what she has heard in the second or third time of listening. The same was the case with IL4 in different wordings: When she listened to tape she tried to check how well she comprehended. Mostly she does this after finishing listening to the text for the first time then she re-listened. The same was with AL1 who said that she asked her lecturer to re-play the listening text to check how much and how well she could understand the next time. LL1 also said that the technique or strategy that could work while listening was checking how much she understood in the second or third time of listening. These indicate that these freshmen employed this strategy to check their comprehension after listening to each part of the listening or their lecturers by thinking back, trying to recall which part of listening they had problems with and in the second or third time of listening, they tried to understand every word and sentences. They tried to judge how well they had understood the conversations and made a decision what problem still existed that avoid them from completing the listening tasks perfectly. However, IL1 described using this strategy in this way: she checked in dictionary to see whether she guessed correctly. In addition, AL2 put it in this way that she tested herself for example she told herself if she had learned this part or not. This indicates that they tried to use their cognitive strengths to analyze carefully and put a great deal of value on revealing their independence by looking for new things (words) in dictionary, checking and finding the answer on their own. Furthermore, IL3 added that the teacher should check the students to see whether the learners pronounce the words, phrases and sentences correctly. This indicates that the instructors and lecturers should also use such strategy (checking) to check their students' receptive language activity in the course of listening tasks to make sure that their students learn well.

In addition, the findings of the think-aloud protocol revealed that all freshmen employed evaluating strategy to facilitate their understanding in the listening process particularly in the second and third time of listening. They all stated that, in the first time of listening they could understand something very general. However, in the second time and third time of listening, they could evaluate their first time of listening. For example, AL4 reported that in the first conversation she heard the word 'video game' she was not sure if the boy was going to play games or watch games. In the second and third time while she was listening to the same conversation, she said that she thought about video game and she wanted to understand what the boy meant by the words 'video games'. These excerpts show that she tried to check what problems she still had that prevented her from completing the listening task. As a result, evaluation is involved in topdown processing in which the listeners utilize their previous knowledge in processing a listening text at any time they are listening (for example in narrow listening each time listening).

\subsection{Imitating and Repeating}

The fourth theme coded as imitating and repeating classified into cognitive category. Imitating what listeners hear and repeating what the learners hear on tapes is another listening strategy used by these freshman learners. By repeating and imitating what the learners hear, they can instill the structures of words, phrases, and sentences employed orally. This can contribute them to reinforce their pronunciation as well as the usage of the grammatical rules or structures in sentences. Repeating words, phrases, or sentences, listening to spoken texts several times, and imitating accents can help listeners become not only familiar with the sounds but also fix the patterns of sentence structures in their minds. Majority of these freshmen reported that they repeat the words, phrases, and sometimes some sentences in order to learn about their pronunciation, accents, and intonations. For example, AL3 said that she liked to listen to the passage several times because in this case she could use more strategies for example, for the first time she listened from the beginning to the end to see how much she has understood, the second time, she listened to the parts that she could not understand the first time. Sometimes before listening to the listening text for the third time she looked up the meaning of the unknown words in a dictionary and listened again. She said that this time she could understand it completely. The same was the case with IL3 in different wordings: when she listened to a text several times, she got used to it. This means that her ears could hear and hear the same accent and she got used to the accent and the next time she intended to listen she could understand better because she was familiar with the pronunciation and accents. In addition, IL2 said that she stopped the tape-recorder a few minutes by a few minutes and repeated what she heard. These indicate that when the 
learners were listening to the spoken texts (conversations) on tape, they tried to listen to it several times so that they could comprehend all the details such as content words and function words as well as distinguishing word boundaries, and interpret word order patterns. They also tried to process the spoken text at different rates of delivery. These freshmen used the technique of repeating the words and phrases or sentences after listening to a spoken text on tapes to achieve correct pronunciation and get familiar with different accents and intonations. The act of listening and practicing with sounds showed that the low learners also tried to adopt this strategy in their effort to improve their English listening skills as LL1 expressed her perception in this way that the accent of a person who spoke English was not familiar and she could not understand, therefore, repetition helped her understand better. She also added that repetition helped her understand well particularly pronunciation. This indicates that repetition is very effective in enhancing comprehension, recognizing the speech sounds and pronunciations.

\subsection{References}

The fifth theme was using dictionary coded as references. The findings showed that all advanced freshmen (AL1, AL2, AL3 and AL4), all intermediate freshmen (IL1, IL2, IL3 and IL4) and three out of four low (LL1, LL2, and LL3) freshmen used references aids such as dictionaries, word notebooks, notes, transcriptions of the listening texts and textbooks to deal directly with English language learning. They reported employing this strategy to help them understand the spoken text. Several freshmen (AL1, AL4, IL3, and LL1) reported that they referred to monolingual (i.e., English-to-English) dictionary to look the new words up. They stated that they looked at their phonetic transcription, parts of speech of the words, grammatical usage, and usage of sentence patterns in their learning processes whereas LL2 and LL3 reported that they used bilingual dictionary (English to Persian) when they were in the class to save the time. They believed that looking up the meaning of words in a monolingual dictionary needs more time because they may find one word in the definition of that word that they may not know the meaning as well. Therefore, it implies that these freshmen should be encouraged to use monolingual dictionaries preferably to enhance their vocabulary repertoires. This strategy classified into cognitive strategies and considered as a kind of interactive processing as the learners interact with dictionaries, word notebooks, notes, and transcriptions of the listening texts.

\subsection{Visualization}

The sixth theme related to cognitive strategies was employing mental imagination coded as visualization. Two out of four advanced freshmen (AL2 and AL3), two out of four intermediate (IL2 and IL3) and one out of four low freshmen (LL1) reported that they used this strategy to comprehend the listening text in narrow listening. To the question, 'what do you do to understand the listening text for the second time or third time?' They asserted that they tried to imagine the keywords and questions they had browsed earlier in their mind. They also tried to imagine the situation in which the conversation took place. They tried to form a relevant picture of what they listened to during the lesson. This indicates that by drawing a picture in their mind related to the conversations the freshmen were able to utilize top-down process and tried to make a connection between new information and the situation where the conversation took place to generate an acceptable general interpretation of it. However, some of these freshmen such as IL3 relied on the images came from the real resources for instance printed pictures in their books. As she said that sometimes when she wanted to listen to the listening text she looked at the book if there was a picture related to that listening text she looked at it and when she was listening she imagined that picture in her mind. This indicates that by imagining picture of the listening text in her mind she tried to understand which part she should focus on more in the second time or third time of listening. This implies that utilizing actual pictures in minds can contribute listeners to represent information and predict what is happening next and when they repeat listening to the same text they can process what they hear.

\subsection{Note-taking while listening}

The seventh theme was making notes while listening coded as note-taking which refers to jotting down some key words, phrases, concepts in abbreviated verbal, graphic, or numerical form to help a listener to understand the listening tasks (Vandergrift, 1997). In other words, listeners employ note-taking strategy in the language learning process by writing down key words, important words, numbers, main points, and questions made by learners. Taking notes reported to be widely utilized by the interviewees in this study when attending to their English listening tasks in narrow listening. For example, AL1 said that when she knew the listening text would be repeated several times, she tried to write what she heard and in the second and third time she listened to the parts that she could not understand for the first time. She also added that at the end she looked at her notes and comprehended it completely. The same was the case with AL3 who said that she wrote some important words and reviewed for the second or third time what she already wrote to complete her notes. These indicate that they tried to complete their notes any time they were listening to the conversations. These imply that making notes in narrow listening can contribute the learners to complete their incomplete notes that they have made in the first time of listening. This also implies that when the learners listen to a listening text several times, it makes them feel more relaxed and comprehend it more effectively.

\subsection{Asking for help}

The eighth theme was asking questions related to a spoken text coded as asking for help. It refers to when learners ask their lecturers or the person whom they are talking to for repetition, paraphrasing, descriptions and explanations, and examples (Chamot, 1987). Asking questions for clarification classified into socio-affective strategies. It refers to an interactive processing of the listening because listeners have to ask their teachers for clear explanations to solve their listening difficulties. AL1 said that she asked her lecturer for the transcription of the listening text, more explanation, and re-playing the listening text. AL4 also said that she expressed herself through her look that she had not understood 
the lecturer's speech. This indicates that she asked her lecturer to repeat her speech. Another freshman (IL3) said that when there was no listening transcription at the end of the book she asked her lecturer for it and more explanation. IL2 said that she asked her lecturer to paraphrase and speak more slowly. LL2 in another words said that she asked her lecturer some questions that help her understand better and LL3 said that she asked the others. These statements indicate that the learners asked for listening transcription, replaying the tapes, repeating, speaking more slowly and paraphrasing the spoken texts. These also show that they asked their lecturers or friends about their problematic points they faced while listening to spoken texts. On the other hand, AL3 reported that she shies to ask her lecturers to repeat in the classroom. The researcher asked this freshman "So how does she try to understand her lecturers' speech while listening to her/him?" She [the interviewee] replied that after class she might ask her friends or ignore it. This indicates that lecturers should make a friendly situation in the class as much as they can in order to make the class atmosphere relaxed for shy learners.

\subsection{Self-talk}

The ninth theme related to socio-affective strategies coded as self-talk. AL3 stated that sometimes she told herself that she had problems in listening and the other students were similar to her so she should do her best to understand. IL1 also expressed a similar perception with the following comment. She said that when she could not understand she told herself that she could understand a few sentences at least and she should not be worried and sad. AL1 also stated that she tried to have enough self-confidence while she was listening to a spoken text. The same was the case with IL2 who said that she tried to listen with a very high self-confidence and sometimes motivation helped her go ahead by listening to her favorite songs in English. These indicate that these freshmen tried to keep self-confidence, have strong motivation, not get sad, keep calm and not get disappointed using this strategy. These also show that in order to be successful in comprehending the listening texts, the listeners should try to increase their self-confidence and should have strong motivation in order to learn a foreign language efficiently. It implies that thinking positively influences the freshmen's feelings and learning activities particularly when they are listening to a spoken language because it also takes in the learners' focus from what they are listening to. In other words, if the learners feel stressed while listening to a foreign language, they lose confidence and concentration and they cannot comprehend the spoken texts.

\subsection{Autonomous Learning}

The tenth theme was studying autonomously coded as autonomous learning classified into meta-cognitive strategies. The freshmen (AL4, IL2, LL3, AL3, and IL3) reported that although they listened to tapes and lecturers in English Language Laboratory Classrooms, they sometimes listened to some English programs on Channel 4, bought books with cassettes and listened to BBC and VOA. Sometimes they watched movies in English although they might not understand well, and listened to the recorded teachers' voices several times. These indicate that they listened to English listening programs on Channel four on TV and sometimes recorded some interesting listening texts and listened to it several times to make each word and sentence meaningful. These also indicate that these freshmen were interested in learning the new language perfectly. It implies that autonomous learning in general and listening in particular is a sort of strategy used by these freshmen to record lecturers' speech, watch TV programs in English, listen to BBC and VOA, use textbooks along with tapes and listen purposefully. Therefore, it is worth asserting that recording the spoken texts and listening to it carefully in order to comprehend the details can be involved in interactive, top-down and bottom-up processing because listeners fully involve themselves in English learning in general and listening in particular. By using bottom-up strategies listeners can rely on the language in the listening texts such as sounds, words, and grammar that make the spoken text meaningful. In other words, they can interact with listening texts, and utilize both top-down and bottom-up processing to comprehend the listening text completely.

\subsection{Word-by-Word or Sentence-by-Sentence Attention}

The eleventh theme was paying attention to words and sentences coded as word-by-word and sentence-by-sentence attention. AL2 said that she always listened word by word and tried to understand any words. The same was the case with IL2 who said that she tried to recognize the words in the sentence, by paying attention to each sound because sometimes some words were different in one letter. AL4 also said that sometimes some words such as subjects, verbs can help her understand the listening. IL1 expressed herself in a different wording. She tried to pay attention to all words and phrases. She wrote the words she heard and tried to identify between sounds sometimes compare with Farsi. AL4 also said that she listened to follow word by word and stop the tape to understand any word. These indicate that these freshmen paid attention to details, content words and function words. They tried to realize word-order patterns, recognize words, phrases and sentences, and recognize phonemic pairs. This implies that understanding all words of the spoken texts make listening texts comprehensible in narrow listening. However, LL3 exclaimed that if she intended to listen to each word for the first time she lost getting the meaning and main idea. Thus, she tried to listen from beginning to the end to get the general ideas and then in the second and third time of listening she tried to analyze each word to understand completely. LL3 expressed her opinion in this way: words, pronunciations, intonations and accents were very important because if she knew these she could get the meaning of the words better. This indicates that in narrow listening learners attempt to use bottom-up processing more often than top-down processing to analyze what they hear by listening to the spoken texts repeatedly and paying attention to micro-skills of listening. In other words, these learners may utilize bottom-up approaches more frequently than top-down approaches since they keep themselves flexible in order to understand the spoken text. 


\subsection{Change the Speech Rate}

The twelfth theme was listening with different speed rates coded as change the speech rate. Most participants reported that because they intended to learn everything on tape or what they were listening to, they recorded and listened to it several times with different rate of speech, from slow to fast. For example, IL2 said that in the second or third time of listening to a spoken text she slowed down the speed of the tape-recorder to recognize the word. She also added that she recorded and listened to it several times with different rate of speech, from slow to fast. However, LL2 said that she listened to the spoken text on tape with normal speed in the first time then in the second time she listened with the lower speed to recognize words and sounds. She also added that then she tried to re-listen to it with its normal speed and compare to see how well she could understand in the third time of listening. This indicates that the freshmen had difficulties in identifying words because of the fast rate of speech in the first time of listening. This implies that the rate of speech can be effective in understanding the spoken text. It also implies that listening to the same spoken text several times (narrow listening) is helpful to the learners particularly low-proficient learners because according to Goh (2000), learners can fix the new input in their memory by paying attention to specific parts of the listening texts and details.

\section{Discussions}

Iranian EFL freshman learners seemed to approach listening as a task primarily requiring comprehension of words, phrases, and sentences while engaged in narrow listening (listening to a listening text several times). In narrow listening, the learners focused on the conversations. They did perception (concentrated and employed selective attention) and parsing (top-down strategies were preferred) and then they reached the phase of parsing or utilization (drawing on personal experience and world knowledge). In other words, they employed their background knowledge and drew on their personal experiences and world knowledge. They also used their linguistic knowledge to understand the listening texts because the conversations repeated three times the learners could easily do three stages to achieve the conversations. Narrow listening contributed the learners to employ particular meta-cognitive (attention, readiness, evaluating/checking, autonomous learning, and change the speech rates), cognitive (imitating and repeating, references/aids, visualization, note-taking and word-by-word/sentence-by-sentence attention), and socio-affective (ask for help and self-talk/expressing inner feelings) listening strategies to understand the spoken texts (conversations) by involving in perception, parsing and utilization. For example, after the learners listened to the conversations for the first time, they were able to know which parts they had already understood and which parts they had not understood yet. Hence, they employed certain strategies in the second time of listening to help them plan to listen for the listening parts of the conversations they had not understood in the first time of listening (planning). In other words, some parts of the conversations became automatic (Anderson 1983, 1995), thus, the learners began to infer the meaning of unknown words (inference). It is worth asserting that when the listening texts are repeated several times (Krashen 1996; Dupuy 1999; Liu 2006), the learners understand the listening texts better as a result of this; the learners are more likely to succeed in employing listening strategies (meta-cognitive, cognitive, and socio-affective) while listening to a spoken text (Liu 2006).

Although advanced freshman learners employed such strategies more frequently, the intermediate and low English listening proficiency level learners also used them. The learners tried to think about the ways in which they could attend to, plan, make decisions, monitor, and evaluate their listening. They tried to pay attention to specific items of the target language (English) such as sounds, words, phrases and grammatical units. In other words, they tried to concentrate on keywords, pronunciation of words, intonation and tone of voice, parts of speech of the words, and accent. They also paid attention to the questions they wanted to find answers for, concentrated on the specific aspects of the listening input and situational details that contributed them to understand the spoken texts. They had a plan on how to listen to a lecturer and a spoken text on tapes and tried to adjust their interpretations if they recognized that they were making mistakes. They relied on the language in the text, the combination of sounds, words, and grammar that created meaning by using bottom-up strategies. This means that by using bottom-up strategies the learners tried to rely on the language in the listening texts such as sounds, words, and grammar that made the spoken text meaningful. Thus, narrow listening lead learners to employ not only top-down strategies but also bottom-up strategies to understand all details. In other words, narrow listening, which is a pleasant way to achieve comprehensible input, lets listeners use more listening strategies to understand the listening texts. This study revealed that meta-cognitive and cognitive strategies were confirmed by the findings achieved through think-aloud protocol. However, there were no socio-affective strategies found by utilizing think-aloud protocol in narrow listening. During the think-aloud sessions, listeners may not remember all the strategies completely. As Vandergrift (2003) asserted the nature of think-aloud is not conducive and helpful to draw out responses to reveal the learners' use of socio-affective strategies. Therefore, second/foreign language (L2/FL) learners with different English listening proficiency levels can use a wide variety of strategies while engaged in narrow listening to understand the listening texts.

\section{Implications}

The findings of this study have practical implications for both lecturers who expect their students to be good English language listeners and Iranian EFL freshman university learners who intend to improve and develop their listening skills while learning a foreign language in Iran. In other words, the results serve as a strategy-based instruction for lecturers who want to teach their students listening strategies so that their students can use them efficiently in narrow listening. This study also implies that lecturers should make their students aware of both top-down strategies and bottom-up strategies. In other words, in narrow listening, students should learn how to develop both bottom-up and topdown processing to understand a spoken text. They should also be able to recognize phonological, morphological 
elements, recognizing words, phrases, and sentences. Lecturers should also make their students aware of these strategies in order to help them comprehend the listening texts. Therefore, EFL learners should be aware of micro-skills and macro-skills of listening. This study also implies that according to Liu (2006), narrow listening makes listeners use progressively more and more listening strategies since it enables listeners to involve more fully in all three listening comprehension processing (perception, parsing, and utilization). Lecturers should also encourage their students of different listening proficiency levels to utilize listening strategies. These are essential in their learning process in general and listening process in particular to develop their listening skills while learning a new language. It is also the lecturers' role to provide learners with the use of listening strategies in their teaching. The students need to be trained how to use specific strategies to improve their listening skills.

\section{Conclusions}

This study was designed to explore the strategies employed by Iranian EFL freshman university learners in narrow listening (listening to a spoken text several times) and how they try to use these strategies. Hence, by conducting the Oxford Placement Test (OPT) developed by (Oxford University Press, Allan 1992), the learners were grouped into three different English listening proficiency levels: the advanced, intermediate, and low freshman learners. The results of both interviews and think-aloud protocols indicated that the advanced, intermediate, and low level of English listening proficiency freshmen in this study were able to describe the strategies employed in narrow listening effectively. They were able to employ meta-cognitive and cognitive strategies more frequently and actively followed by socio-affective strategies. Thus, it is concluded that listening to the same spoken text several times (narrow listening) can be helpful to these learners particularly lower-proficient learners because they can fix the new input in their memory by paying attention to specific parts of listening and details as they repeat the spoken texts. They also like to employ not only top-down strategies but also bottom-up strategies to understand everything. It is also concluded that having interaction with lecturers for assessment and evaluation and other aims while listening contribute listeners to remove confusion and utilize their newly gained knowledge immediately and make it regular in use. Being aware of these strategies contribute them to understand the spoken language better, faster and as a result, reply instantly and appropriately; not having to frequently shrug their shoulders and saying "I don't know". Also, it is concluded that the importance of listening in the second/foreign language learning should never be neglected particularly in the EFL contexts such as Iran. Iranian EFL freshman university learners need to have strong listening skills and strategies to access the wide variety of activities and tasks that involve oral input; particularly when they need to listen to lectures or talk in the second/foreign language. Strategy awareness should be taken into account and considered as parts of EFL learners' learning schedule. Therefore, narrow listening can effectively promote second language listeners to employ strategies more frequently while they are listening to a spoken text or when listening to someone speaking in their target language.

\section{References}

Allan, D. (1992). Oxford placement test. Oxford: Oxford University Press.

Anderson, J.R. (1983). The architecture of cognition. Cambridge, M A: Harvard University Press.

Anderson, J. R. (1995). Cognitive psychology and its implications. 4th Edition. New York: W. H. Freeman and Company.

Brown, R. A. (2005). Autonomous Learning Strategies of Japanese EFL Students. The Language Teacher, 29(4), 11-14.

Brown, R. A. (2007). Enhancing motivation through repeated listening. Information \& Communication Studies, 37, 915. Chigasaki, Japan: Bunkyo University.

Caspino, B. K. (2005). Support for narrow listening libraries. The International Journal of Foreign Language Teaching, IJELT 1(4), 2-9.

Chamot, A. U. (1987). The learning strategies of ESL students. In A. Wenden, \& Rubin (Ed.). Learner strategies in language learning (pp. 71-83). Prentice-Hall International (UK) Ltd.

Creswell, J. W. (2002). Educational research: Planning, conducting, and evaluating quantitative and qualitative research. Upper Saddle River, New Jersey Columbus, Ohio. Merrill Prentice Hall. University of Nebraska-Lincoln.

Dunkel, P. (1991). Listening in the native and second/foreign language: Toward an integration of research and practice. TESOL Quarterly, 25, 431-457.

Dupuy, B.C. (1999). Narrow listening: an alternative way to develop and enhance listening comprehension in students of French as a foreign language. System, 27, 351-361.

Flowerdew, J., \& Miller. L. (2005). Second language listening: Theory and practice. Cambridge: Cambridge University Press.

Goh, C. C. (1998). How ESL learners with different listening abilities use comprehension strategies and tactics. Language Teaching Research 2 (2):124-147.

Goh, C. C. M. (2000). A cognitive perspective on language learners' listening comprehension problems. System 28 (1):55-57.

Jensen, E. D., \& Vinther, T. (2003). Exact repetition as input enhancement in second language acquisition. Language 
Learning, 53, 373-428.

Krashen, S. (1996). The case for Narrow Listening. System, 24(1), 96-100.

Liu, M. M. (2006). Extensive or repeated? A comparison of their effects on the use of listening strategies. University of Oxford, Dept of Educational Studies.

Macaro, E. (2003). Teaching and learning a second language. London: YHT Ltd.

Nunan, D. (1999). Second language teaching and learning. Boston, Massachusetts 02116 U.S.A.: Heinle and Heinle, An International Thomson Publish.

O'Malley, J. M., Chamot, A. U., \& Kupper, L. (1989). Listening comprehension strategies in second language acquisition. Applied Linguistics, 10 (4), 418-437.

O'Malley, M. J., \& Chamot, A. U. (1990). Learning strategies in second language acquisition. England: Cambridge University Press.

Rost, M. (2002). Teaching and researching listening. London: Longman.

Richards, J. C. (2005). Interchange Intro. 3ed. Cambridge: Cambridge University Press.

Richards, K. (2003). Qualitative inquiry in TESOL. New York: Palgrave Macmillan.

Smidt, E., \& Hegelheimer, V. (2004). Effects of online academic lectures on ESL listening comprehension, incidental vocabulary, and strategy use. Computer Assisted Language Learning, 17, 517-556.

Strauss, A. L. \& Corbin, J. M. (1998). Basics of qualitative research: Techniques and procedures for developing grounded theory. California: Sage Publications, Inc.

Tokeshi, M. (2006). Listening comprehension processes of six Japanese junior high school students in interactive settings. The Language Teacher, 30 (1), 3-7

Vandergrift, L. (1992). The comprehension strategies of second language (French) listeners. PhD Thesis, University of Alberta, Canada.

Vandergrift, L. (1996). Listening strategies of Core French high school students. Canadian Modern Language Review, 52 (2), 200-223.

Vandergrift, L. (1997). The comprehension strategies of second language (French) listeners: A descriptive study. Foreign Language Annals, 30, 387-409.

Vandergrift, L. (1999). Facilitating second language listening comprehension: acquiring successful strategies. EFL Journal, 53 (3), 168-176.

Vandergrift, L. (2007). Recent developments in second and foreign language listening comprehension research, Language Teaching, 40, 191-210.

Vandergrift, L. (2011). Second language listening: presage, process, product, and pedagogy. In Eli Hinkel (Ed). Handbook of research in second language teaching and learning, Volume II. (pp. 455-471). New York: Routledge, Taylor \& Francis.

Yang, C. (2009). A study of meta-cognitive strategies employed by English listeners in an EFL setting. International Education Studies, 2 (4), 134-139.

Younezawa, M. and Ware, J. L. (2008). Examining extensive listening. In K. Bradford-Watts, T. Muller, \& m. Swanson (Eds), JALT 2007 Conference Proceedings. Tokyo: JALT. 